\title{
Research Design of Mobile Based Decision Support for Early Flood Warning System
}

\author{
https://doi.org/10.3991/ijim.v14i17.16557 \\ Mohd Faizal Omar ${ }^{(\bowtie)}$ \\ Universiti Utara Malaysia, Kedah, Malaysia \\ Centre for Testing, Measurement and Appraisal (CeTMA), \\ Universiti Utara Malaysia, Kedah, Malaysia \\ faizal_omar@uum.edu.my \\ Mohd Nasrun Mohd Nawi \\ Universiti Utara Malaysia, Kedah, Malaysia \\ Disaster Management Institute (DMI), Universiti Utara Malaysia \\ Kedah, Malaysia \\ Jastini Mohd Jamil \\ Universiti Utara Malaysia, Kedah, Malaysia \\ Ani Munirah Mohamad \\ School of Law, Universiti Utara Malaysia, Kedah, Malaysia \\ Centre for Testing, Measurement and Appraisal (CeTMA), \\ Universiti Utara Malaysia, Kedah, Malaysia \\ Saslina Kamaruddin \\ Universiti Pendidikan Sultan Idris, Perak, Malaysia
}

\begin{abstract}
Flooding has become one of the most rapidly growing types of natural disaster that has spread around the globe. It is one of the major natural hazards in many countries and mostly affected in the low-lying or flood prone areas. In order to minimize loss of life and economic losses, a detailed and comprehensive decision-making tool is necessary for both flood control planning and emergency service operations. In this paper, we demonstrate our research design for mobile based decision support of Flood Early Warning System (FEWS). We outlined four research objectives. Firstly, critical criteria for flood risk assessment will be identified and the second step will involve develop measurement model for relative flood risk using Geographic Information System (GIS), Multi Attribute Decision Making (MADM) and data mining technique. In the third objectives, the holistic architectural design is developed by incorporating the communication technology and other related ICT requirements for the mobile decision support. The fourth objective is to validate the mathematical model and architectural design. Case study approach is chosen in order to understand the flood event and validate the decision support model. Following well-defined procedures, flood maps were drawn based on the data collected from expert responses to a questionnaire, the field survey, satellite images, and documents from flood management agencies. It anticipates that by integrating of mathematical model, GIS and
\end{abstract}


mobile application in flood risk assessment could provide useful detailed information for flood risk management, evacuation, communication. The decision support design from this study is perhaps to improve the warning system and contribute to reduction of casualties.

Keywords - Flood Management, Flood Early Warning System, Decision Support System, Multi Attribute Decision Making.

\section{Introduction}

A flood is a natural event that can have far reaching effects on people and the environment. Flood can be defined as relatively high stream flow, which overtops the natural or artificial banks in any part of a stream, river, estuary, lake or dam, and/or overland runoff before entering a watercourse and/or coastal inundation resulting from super elevated sea levels and/or waves overtopping coastline defenses. Given the concepts of flooding that are being addressed, it is essential that the terminology used is consistent and understood. Flood can be defined as a body of water, which rises to overflow land that is not normally submerged [1]. Types of flood in Malaysia are: monsoon flood, urban flash flood, debris flow and mud flow, landslide, tidal flood, dam release, and bund breach [2]. Generally, floods can be classified into two types, which are river floods and coastal floods with different characteristics as follow [3]:

\subsection{River floods}

Floods in river valleys occur mostly on floodplains or wash lands as a result of flow exceeding the capacity of the stream channels and over spilling the natural banks or artificial embankments. Mainstream Flood, inundation of normally dry land occurring when water overflows the natural or artificial banks of a stream, river, estuary, lake or dam [2]. Sometimes inundation of the floodplain, or of other flat areas, occurs in wet conditions when an already shallow water table rises above the level of the ground surface. This type of water table flooding is often an immediate precursor of overspill flooding from the stream channels [3].

In very dry conditions, when the ground surface is baked hard or becomes crusted, extensive flat areas may be flooded by heavy rainfall ponding on the surface. This rainwater flooding is typical of arid and semi-arid environments but is also experienced much more widely [3]. Also typical of arid and semi-arid areas is the situation where there are no clearly defined channels and where sheet wash flooding occurs by the unimpeded lateral spread of water moving down a previously dry or near-dry valley bottom or alluvial fan.

In urban areas flooding often results from over spilling or surface ponding, as described above, but may also occur when urban storm-water drains become surcharged and overflow. Storm water is resulting from runoff from a storm event. During rainfall event some water remains on the surface or is held in the soil or underground aquifer as ground water, a portion of the water is used directly by plants and the remainder 
flows over the surface. This overland flow is called storm water. Local Overland Flood where inundation by local runoff rather than over bank discharge from a stream, river, estuary, lake or dam.

\subsection{Coastal flood}

Floods in low-lying coastal areas, including estuaries and deltas, involve the inundation of land by brackish or saline water. Brackish-water floods result when river water overspills embankments in coastal reaches as flow into the sea is impeded by high-tide conditions. Overspill is exacerbated when high-tide levels are increased above normal by storm-surge conditions or when large freshwater flood flows are moving down an estuary [3]. Direct inundation by saline water floods may occur when exceptionally large wind-generated waves are driven into semi-enclosed bays during severe storm or storm-surge conditions, or when so-called 'tidal waves', generated by tectonic activity, move into shallow coastal waters.

\section{Issues in Flood Management}

Generally, a flood is caused by a combination of heavy rainfall causing river or coastal to over flow from their banks, and can happen at any time of the year. Most river floods result directly or indirectly from climatologically events such as excessively heavy and/or excessively prolonged rainfall. In cold-winter areas, where snowfall accumulates, substantial flooding usually occurs during the period of snowmelt and ice melt in spring and early summer, particularly when melt rates are high. River floods may also result when landslides fall directly into upstream lakes or reservoirs causing a sudden rise in water level, which overspills the outlet or dam. Coastal areas are also at risk from sea flooding, where coastal floods are usually caused by a combination of high tides and the elevated sea level and large waves associated with storm surges, which result from severe cyclonic weather systems and low atmospheric pressure.

Incidences of floods in urban areas are on the rise. This is because in new townships, the total impervious areas are very high since the housing developers only have to comply to an open space of $10 \%$; the developers normally go for maximum built up areas to maximize land use. With respect to catchment runoff, an increase in area imperviousness from zero to $40 \%$ would cut the time to peak discharge by about $50 \%$ and increase the discharge magnitude by about $90 \%$ [23]. Before urbanization, rainwater is intercepted by the vegetation, infiltrates into the ground and takes time to travel to the river, but now it is quickly collected from the roofs and other paved grounds and canalized efficiently to public drains, which in turn rapidly brings it to the nearest river. Although floods are natural phenomena, the effects of rainfall resulting in excess water running into streams and rivers, uncontrolled development activities in watersheds and along river corridors and high sea level areas can increase the severity of floods. The high rate of sedimentation in the rivers can also lead to serious flooding.

The annual costs incurred by the Malaysian Government in flood disaster preparedness, rescue and relief operations, and post-flood rehabilitation of victims and public 
utilities are substantial. While loss of life due to flooding in the peninsular is not as severe as in Bangladesh or elsewhere in the world, it is nevertheless significant. Flood damages are based on crudely estimated damage to crops and livestock, public structures and properties, and interrupted activities and rescue and relief. The damage figures shown are substantial and would be much higher if damage to private properties were included. The potential flood damage in large urban centre such as Kuala Lumpur can be high. As a result, the Government of Malaysia has designated the government department notably the Department of Irrigation and Drainage as well as agencies to execute strategic decisions to reduce the impact and negative effect of floods.

In our proposed work, we outlined three research questions as follows: (1) What are the criteria to prepare a flood hazard/risk map in Malaysia? (2) How to measure flood risk and map indexing for a specific area in Malaysia? (3) What are the requirements dimensions for Mobile Decision Support for Early Flood Warning System in Malaysia?

\section{Flood Early Warning System}

One of the remedial measures that have been carried out is the development of the flood warning system where the information system plays the major role to get the information from all the stations situated along the river bank, process the information and channel the information to the appropriate authority for further immediate response. Although the system is very reliable in transmitting flood information, but have generally little effect in reducing the problem. However, it is now understood that it is neither possible nor desirable to control floods completely. A geographic information system (GIS) is thus being increasingly recognized as the most effective approach to flood disaster management. It is for this reason that, the research on flood warning system utilizing GIS has been executed. This GIS will be integrated with mathematical modelling in the collection and processing of data and the development of applications that monitor and create a proper awareness of likely flood disasters and their impact. The changing trends and advancement of GIS technologies and mathematical modelling have enabled their application in a large number of scientific and technological resources and skills developments to reduce flood disasters. These developments include their real-time applications in suitable early warning systems, preparedness and overall flood disaster management. The system emphasizes the estimation of flood plain as an aspect of flood disaster management, which was generally neglected in previous management plans in Malaysia. Expected flood inundation maps are then produced to form the basis of advance warnings of impending floods well before they actually occur.

In the last few years, a large number of projects aimed at the development of stronger and "smarter" flood protection systems have been initiated around the world. All of them aim to solve flood control problems, and several by developing Flood Early Warning Systems (FEWS). Existing EWSs are mostly localized, custom-designed and using local computer resources. State-of-the-art flood early warning systems use meteorological data, water levels and remote satellite monitoring data (optionally) as input sources [4-7]. However, in Malaysia the concept of FEWS is still new and there is a need to develop a better decision support system for the government agency and disseminate 
the result to affected community in real time. This mission critical activity is vital in order to minimize the loss particularly in East Coast State in Malaysia during the monsoon season.

\section{Decision Support System}

Historically, DSS research began in the 1960s where the emphasis of the researches was more on conceptual aspects of decision making [8]. Later, a more refined decision support framework was developed which incorporated categories of management activities and descriptions of decision type [9]. These include management activities such as strategic planning, management control and operational control. The proposed framework is a combination of Antony's management activities and Simon's Model explanation of decision types, which comprises structured, unstructured and semi-structured. DSS usually being develop to solve Multi Attribute Decision Making (MADM) problem [10-12]. Example of MADM problem includes project selection, contractor selection, supplier selection, consultant selection, etc. [14-18]. According to [13], MADM problem involves the selection of the 'best' alternative from a pool of preselected alternatives described in terms of their criteria.

\section{Mobile Decision Support System for FEWS}

Recent growth and advances in mobile computing and communication have revolutionized the way we live and access information. Today we are able to receive and process a vast amount of real-time data and situational information on mobile devices in a manner that has not been witnessed previously. Mobile devices in general are portable devices that are able to communicate with each other using wireless networks, Internet, or other protocols [19]. They can be classified into different categories. Among these categories, smart-phones, PDAs and tablets are the most widely used devices to support mobile decision sup-port systems as well as being greatly popular with general users [20]. Smart phones enable the use of the Internet on the move and have introduced new perspectives on the use of mobile devices. Although traditional DSS is often accommodated by desktop computers, [20] predicted that the blooming of mobile technology and mobile devices would bring a lot more opportunities for DSS. One of the main benefits that mobile technology offers to decision support systems is the ability to retrieve real-time information anywhere, anytime [21]. Mobile DSS provides a ubiquitous working environment in situations that require high mobility.

Research in Mobile DSS is growing since the introduction of smartphones such as Android and IOS device. However, limited study has been performed for FEWS using mobile device for the client side. Therefore, a location-based software is desirable to help the community combating the flood issue. Hence, we intend to conduct a requirement analysis in order to develop a framework for location-based decision support for FEWS in Malaysia.

Figure 1 illustrates and example of risk mapping system in Japan [22]. This conceptual model of decision support has the potential to be deployed in a server. However, 
the information needs to distributed to the community in order to minimize the losses. For example, in Malaysia, the information regarding the risk and mapping of each sector can be disseminate through mobile device which is similar to location-based application such as Waze, Google Maps, Navigator, etc.

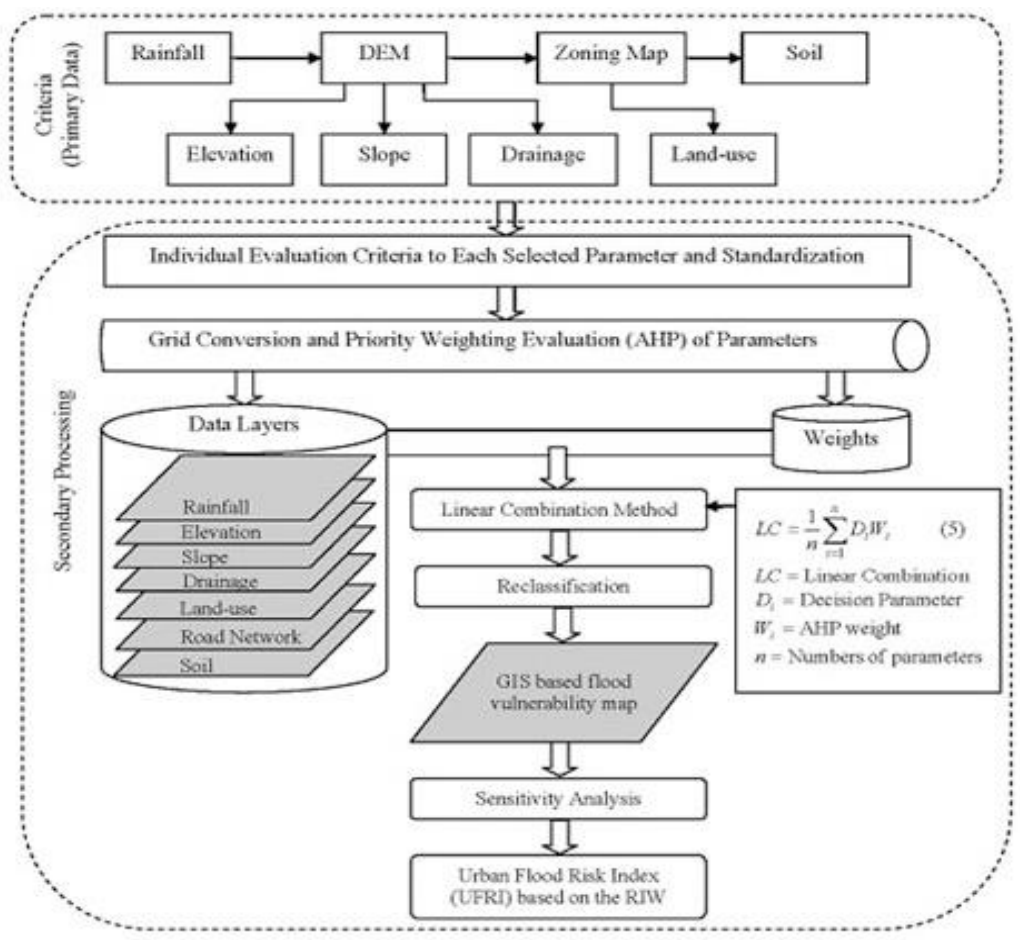

Fig. 1. Conceptual Model of Flood Risk and Mapping [22]

\section{Research Methodology for Mobile Based Decision Support System}

The proposed research phases are as follows:

Phase 1: Awareness of the problem

The first phase research starts with the awareness of the problems. The literature review is the only activities in this phase. The output at this stage is the critical review of FEWS, and adaptive Requirement Engineering.

Phase 2: Mobile based FEWS requirement analysis and design

The second phase of the research concerns on the design aspect of mobile based FEWS. It involves a case study of requirement analysis which will perform an in-depth investigation of system requirements in terms of the ecosystem, user, technology and process modelling in flood monitoring for river Basin in Kelantan and Kubang Pasu in Kedah. Data collection techniques will involve documental analysis, interviews and 
focus group discussion with experts from related government agencies. The case study will be used to justify the tentative architectural design for mobile based FEWS using Goal Requirement Analysis, computation of risk using Fuzzy TOPSIS and data mining, and mapping risks to locality on mobile application and its communication elements.

\section{Phase 3: The validation of mobile based FEWS}

The model will be tested and validate through case study to demonstrate the proposed approach. A tentative architectural design of mobile based decision support FEWS will be presented. Each sector or block will be associated with a risk value (that was previously been calculated based on Fuzzy TOPSIS and data mining) on the server side and they will be shared with user maps on the client side (mobile device).

\section{Phase 4: Deliverable and conclusions}

This is the final phase of the research where it will conclude and summarize the findings. Deliverables of this phase is the revised software specification of for mobile based decision support FEWS. Thus, this will directly address the main research aim.

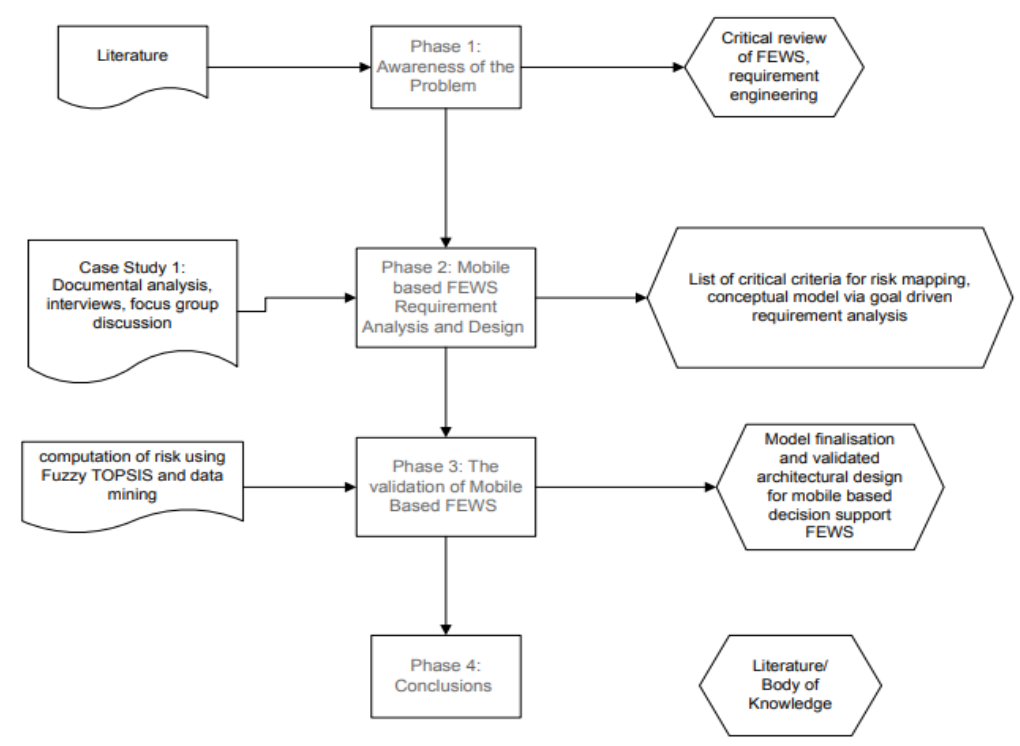

Fig. 2. Research Phases for Mobile based FEWS

\section{$7 \quad$ Discussion and Conclusion}

The annual costs incurred by the Malaysian Government in flood disaster preparedness, rescue and relief operations, and post-flood rehabilitation of victims and public utilities are substantial. While loss of life due to flooding in the peninsular is not as severe as in Bangladesh or elsewhere in the world, it is nevertheless significant. Flood damages are based on crudely estimated damage to crops and livestock, public structures and properties, and interrupted activities and rescue and relief. The damage figures shown are substantial and would be much higher if damage to private properties were 
included. The potential flood damage in large urban centre such as Kuala Lumpur can be high [23]. As a result, the Government of Malaysia has designated the government department notably the Department of Irrigation and Drainage as well as agencies to execute strategic decisions to reduce the impact and negative effect of floods.

One of the remedial measures that have been carried out is the development of the flood warning system where the Information System plays the major role to get the information from all the stations situated along the river bank, process the information and channel the information to the appropriate authority for further immediate response. Decision Support System is a type of Information System that support decision making and it has been applied to a wide range of applications [24-26]. DSS has the potential to support flood warning system with the combination of other technology such as GIS,

A GIS is recognized as the most effective approach to flood disaster management. It is for this reason that, the research on flood warning system utilizing GIS has been executed. This GIS will be integrated with mathematical modelling in the collection and processing of data and the development of applications that monitor and create a proper awareness of likely flood disasters and their impact. The changing trends and advancement of GIS technologies and mathematical modelling have enabled their application in a large number of scientific and technological resources and skills developments to reduce flood disasters. These developments include their real-time applications in suitable early warning systems, preparedness and overall flood disaster management. The system emphasizes the estimation of flood plain as an aspect of flood disaster management. Expected flood inundation maps are then produced to form the basis of advance warnings of impending floods well before they actually occur.

In this paper, we have outlined our research approach to developed mobile based FEWS in Malaysia. Our future works will consist of document analysis, semi-structured interviews, system development, experimentation and usability evaluation.

\section{$8 \quad$ References}

[1] Chow, V.T., Maidment, D., and Mays, L. W., (1988). Applied Hydrology. McGraw Hill.

[2] Izumi, T., Matsuura, S., Mohd Yusof, A.F., Razak, K.A., Moriguchi, S., Kure, S., Jamal, M.H., Motoyama, E., Supar, L.M. (2019). Disaster Risk Report by IRIDeS, Japan; Universiti Teknologi Malaysia; Selangor Disaster Management Unit, Selangor State Government, Malaysia

[3] Smith, K., R. and Ward, 1998. Floods: Physical processes and human impacts. John Wiley and Sons, Chichester, UK.

[4] Bandon (2011) Official website Bandon Flood Early Warning System http://www.bandonfloodwarning.ie/

[5] FEWS NET by USGS (2008) http://international.usgs.gov/projects/prifewsnet.htm

[6] Flash (2010) "Flash Flood Early Warning System Reference Guide". University Corporation for Atmospheric Research http://www.meted.ucar.edu/hazwarnsys/haz fflood.php

[7] Delft-FEWS (2009) Hydrological forecasting and warning system, http://www.deltares.nl/en/software/479962/delft-fews

[8] Simon, H. A. (1960). The Ford distinguished lectures: Vol. 3. The new science of management decision. Harper \& Brothers. 
[9] Kirs, P., Sanders, G., Cerveny, R., \& Robey, D. (1989). An Experimental Validation of the Gorry and Scott Morton Framework. MIS Quarterly, 13(2), 183-197. https://doi.org/10. 2307/248926

[10] Thakur, D. (2020). Anthony's Framework for Understanding MIS. http://ecomputernotes.com/mis/information-and-system-concepts/anthonysframework

[11] Omar, M.F., Nawi, M.N.M., Nursal, A.T. (2014). Decision support framework: A review study of building information modelling software selection in construction project management. Advances in Environmental Biology, 8 (22), pp. 54-57

[12] Nursal, A.T., Omar, M.F., Nawi, M.N.M. (2015). Decision support evaluation for building information modeling software selection. Jurnal Teknologi, 75 (9), pp. 117122.https://doi.org/10.11113/jt.v75.5245

[13] Lu, J., Zhang (2007). Multi-objective Group Decision Making: Methods Software and Applications with Fuzzy Set Techniques. London, UK, Imperial Colleage Press.

[14] Nursal, A.T., Omar, M.F., Nawi, M.N.M. (2015). The design of topsis4BIM decision support for building information modeling software selection. Jurnal Teknologi, 77 (5), pp. 17. https://doi.org/10.11113/jt.v77.6106

[15] Maram, V., Sultan, S.J., Omar, M.F.B., Bommisetty, V.N.R. (2019). Selection of software in manufacturing operations using analytic hierarchy process. AIP Conference Proceedings. https://doi.org/10.1063/1.5121095

[16] Sahamir, S.R., Zakaria, R., Omar, M.F., Shakri, M.R., Chughtai, M.W., Mustafar, M., Rooshdi, R.R.R.M. (2019). Energy Efficiency Criteria for Planning and Design of Green Hospital Buildings Rating System. IOP Conference Series: Materials Science and Engineering, 620 (1). https://doi.org/10.1088/1757-899x/620/1/012082

[17] Omar, M.F.B., Trigunarsyah, B., Wong, J. (2018). Two-envelope system for consultant selection using Weighted Sum Model. International Journal of Engineering and Technology (UAE), 7 (4), pp. 121-125. https://doi.org/10.14419/ijet.v7i4.27.22498

[18] Omar, M.F., Nursal, A.T., Nawi, M.N.M. (2018). Vendor selection in Industrialised Building System (IBS) with topsis under fuzzy environment. Malaysian Construction Research Journal, 3 (Special Issue 1), pp. 163-177.

[19] Burstein, F., Brezillon, P., Zaslavsky, A. (2011). Introducing context into decision support on the move. In (eds) F. Burstein, P. Brézillon, \& A. Zaslavsky (Eds.), Supporting real-time decision-making: The role of context in decision support on the move (pp. XXXIIIXXXIX). New York: Springer. https://doi.org/10.1007/978-1-4419-7406-8

[20] Turban, E., Aronson, J., \& Liang, T. (2005). Decision Support Systems and Intelligent Systems. 7th Edition. Prentice Hall

[21] Omar, M.F., Trigunarsyah, B., \& Wong, J.K.W (2011). Sustainable Infrastructure Project Planning: Progress in Contemporary Decision Support Tools. In Rethinking Sustainable Development: Urban Management, Engineering, and Design. IGI Global, Hershey PA, USA. https://doi.org/10.4018/978-1-61692-022-7.ch018

[22] Ouma, Y.O.; Tateishi, R. (2014) Urban Flood Vulnerability and Risk Mapping Using Integrated Multi-Parametric AHP and GIS: Methodological Overview and Case Study Assessment. Water 2014, 6, 1515-1545. https://doi.org/10.3390/w6061515

[23] Ashaari, M.A.M. (2008). Flood Problem at Junction Kg. Sentang: It causes and the Engineering Solutions. Dissertation, Universiti Teknologi Petronas.

[24] Omar, M.F., Mahathir, N. H., Nawi, M.N.M, Zulhumadi, F. (2019). Prototype development and pre-commercialization strategies for mobile based property analytics. International Journal of Interactive Mobile Technologies (iJIM), 13 (10), pp 198-204. https://doi.org/10.3991/ ijim.v13i10.11309 
[25] Effendy, F. (2020). Mobile Based Decision Support System of Supplier Evaluation. International Journal of Interactive Mobile Technologies (iJIM), 14 (04), pp 61-73. https://doi.org/10.3991/ijim.v14i04.11371

[26] Omar, M.F., Roshidi, S.R.A., Jamil, J.M., Kamal, F.M., Nawi, M.N.M., Radzuan, K. (2019). Towards designing tools for universities' R\&D performance measurement on Mobile Platform. International Journal of Interactive Mobile Technologies (iJIM), 13 (04), pp 178-187. https://doi.org/10.3991/ijim.v13i04.10547

\section{Authors}

Mohd Faizal Omar is a senior lecturer at Universiti Utara Malaysia and received his PhD from Science and Engineering Faculty, Queensland University of Technology, Brisbane, Australia. His research work mainly focus on developing analytical tool by using Artificial Intelligence and Operation Research; to wide area of applications such as R\&D performance measurement, built environment, manufacturing, business management, etc. In addition, Faizal is currently attached with School of Quantitative Sciences and Center for Testing, Measurement and Appraisal (CeTMA) as a Research Fellow.Email: faizal_omar@uum.edu.my

Mohd Nasrun Mohd Nawi specializes in the area of integrated design and construction management. He holds a PhD the field of Construction Project Management from the University of Salford, UK. As an academician and a fully qualified Building Surveyor, he has been active in research and consultation works relating to the areas of Industrialised (offsite) and Modern Method of Construction, Integrated Design Delivery Solution (i.e. Integrated Project Delivery, Lean Construction, Building Information Modelling), Sustainable (green) Construction, Life cycle costing \& Value Management, Building Performance (i.e. Energy Management and Audit) and Management of Technology. Besides being involved actively in various academic activities, he is also an active author with various publications especially in the area of Construction and Technology Management. Email: nasrun@uum.edu.my

Jastini Mohd Jamil is a senior lecturer and researcher in Data Mining at School of Quantitative Sciences, Universiti Utara Malaysia. She received his Ph.D in Data Mining from University of Bradford in 2012. Her doctoral thesis work (Partial Least Squares Structural Equation Modelling with Incomplete Data: An Investigation of the impact of statistical and computational imputation methods) used models drawn from customer index satisfaction domains using structural equation modeling to compare statistical imputation methods and computational imputation methods. She also holds a Master of Computer Sciences with focused on data mining, rough sets and neural networks from Universiti Teknologi Malaysia, and a Bachelor degree in Information Technology (networking) with honours from Universiti Utara Malaysia. Her research interests are solving problems in diverse area using data mining, decision support system and statistical techniques. Her other interests include structural equation modeling, partial least squares, neural networks, rough sets, data pre-processing, handling missing data and forecasting. Email: jastini@uum.edu.my

Ani Munirah Mohamad is a senior lecturer at the School of Law, and research fellow at Center for Testing, Measurement and Appraisal (CeTMA), Universiti Utara 
Malaysia, Kedah, Malaysia. She holds a PhD in Law from Universiti Teknologi MARA Selangor, Malaysia, Chartered Islamic Finance Professional (CIFP) from INCEIF, Kuala Lumpur, Malaysia, and Master of Comparative Law (MCL), Bachelor of Law (Hons) (LLB) and Diploma in Shariah law and Practice (DSLP) from International Islamic University Malaysia, Selangor, Malaysia. She frequently publishes in local and international journals in the area of cyber law and information technology law. Today, she is actively engaged in the research area of information and communication technology laws. Email: animunirah@uum.edu.my

Saslina Kamaruddin is a senior lecturer at the Faculty of Management \& Economics, Universiti Pendidikan Sultan Idris. She obtained her Bachelor of Law \& Commerce (Hons.) from the Management \& Science University, her Master of Laws and, and her Ph.D. in Law from the University Teknologi MARA. Currently, she teaches Legal Research Project, Employment Law, Business Law, and Securities Law and International Trade Law for undergraduate students. Her area of interest is the

Anti-money laundering and Anti-terrorist financing laws, criminal law, and prevention/countering of violent extremism related laws. She frequently publishes in local and international journals in the area of anti-money laundering laws and other areas of laws too. Email: saslina@fpe.upsi.edu.my

Article submitted 2020-06-25. Resubmitted 2020-07-26. Final acceptance 2020-07-28. Final version published as submitted by the authors. 